\title{
Archaeological Protein Residues: New Data for Conservation Science
}

\author{
Andrew Barker
}

Author Address: University of North Texas, Department of Biological Sciences, Denton, TX 76203

AndrewBarker@my.unt.edu

Received: August $15^{\text {th }} 2010$

Published: February $17^{\text {th }} 2011$

Volume 1:58-65

(c) 2010 Society of Ethnobiology

Abstract: The utility of zooarchaeological data for addressing wildlife management and conservation research has been increasingly recognized over the past two decades. As the field of 'applied zooarchaeology' continues to grow, newfound opportunities for discovery have arisen via collaborative interdisciplinary approaches. The burgeoning field of proteomics, in particular, has provided numerous opportunities for enhancing the degree to which meaningful information can be recovered from the archaeological record. Archaeological protein residues can inform conservation biologists about paleobiogeography and ecological/evolutionary history and thereby provide insight into wildlife management strategies. In addition to pointing out several cases where archaeological protein residues may be of benefit, I justify the use of protein residues in particular and discuss areas for improvement.

Key Words: Applied Zooarchaeology, Archaeological Residue Analysis, Proteins, Conservation Biology

\section{Introduction}

Zooarchaeological research has the potential to provide valuable data that are relevant to modern wildlife management, particularly in regards to species reintroduction or exotic species extirpation efforts (Lyman 1996). By studying the biogeographic distributions of species and their interactions with humans during prehistoric times via zooarchaeology, a deep temporal perspective is revealed. This is important because evolutionary and ecological change occur on time scales that are longer than the human lifetime and than most written histories (Callicott 2002), meaning that attempts to return an ecosystem to a 'natural' state require careful consideration of its history beyond the past few hundred years.

Following Lyman (1996), many studies (e.g., Cannon and Cannon 2004; Wolverton et al. 2007) have demonstrated the value of zooarchaeological data for addressing important conservation questions. However, the fragmentary nature of the zooarchaeological record, both in terms of the skeletal remains that are preserved over time in addition to the limited geographic areas over which zooarchaeological analyses have been conducted, can be a challenge. Although continued development of methods for the identification of bone fragments and a growing appreciation for the importance of preserving and analyzing the zooarchaeological record go a long way toward addressing these challenges, new developments in the chemical analysis of organic archaeological residues, particularly those of proteins, show promise for providing an alternative line of evidence that can provide similarly valuable data.

As revealed by the steady increase in archaeological publications dealing with residue analysis over the past twenty years (Eerkens and Barnard 2007), archaeologists are increasingly turning to the study of organic residues as a source of information about past cultures. Artifact function, the origins of domestication, the extent of prehistoric trade networks and prehistoric diet, in general, have been revealed through studies examining a range of organic compounds including DNA, lipids, proteins, and alkaloids. Many of these compounds, particularly the more complex and fragile ones, such as DNA and proteins, were originally assumed to preserve poorly over long periods of time. In some instances, this assumption has been verified by studies observing a poor degree of preservation in both experimental and archaeological samples (e.g., Evershed and Tuross 1996). However, other studies have successfully challenged this notion by demonstrating that under certain circumstances (e.g., cold, dry environments, rapid burial, sheltered contexts), these compounds can survive for periods much longer than anticipated. In one of the most surprising recent examples, collagen, a structural protein found in bones, was recovered and identified from a fossilized hadrosaur (Brachylophosaurus canadensis) bone dated to approximately 80,000,000 years ago (Schweitzer et al. 2009). This study and others that demonstrate the preservation of biomolecules in ancient and/or experimental samples suggest that the potential for 


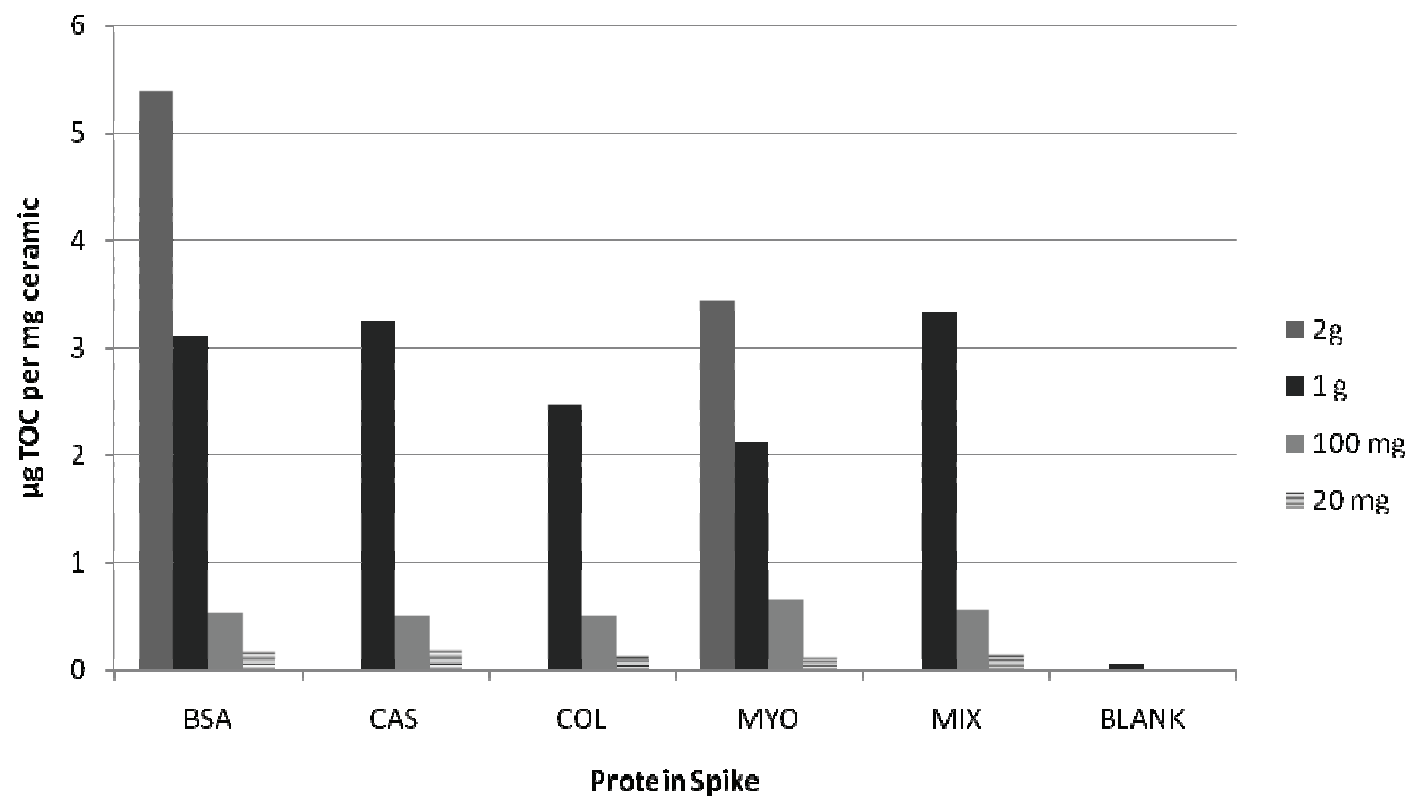

Figure 1. Binding tendencies of different protein types reported by Stevens et al. (2010). Four different proteins (bovine serum albumin, bovine casein, bovine collagen and horse myoglobin), were cooked with ceramic at different ratios. Amounts listed to the right represent quantities of protein cooked with $40 \mathrm{~g}$ of ground ceramic. A mixture of all four proteins, 'MIX' and an unspiked reference sample, 'blank' were also included. The spiked ceramic was washed repeatedly to remove unbound protein and remaining bound protein content was estimated via total organic carbon (TOC) analysis. The results clearly demonstrate that proteins bind to clay matrices despite attempts at removal.

recovery of meaningful ancient biomolecules is much greater than initially expected.

Insofar as conservation science is concerned, this revelation is important because it suggests the feasibility of using organic residues to gain insight into environmental history across broad spatial and temporal scales. As stated by Loy (1983:1270), one of the pioneers of archaeological blood protein residue analysis, "ancient blood proteins from dated contexts will assist in paleozoological and protein-evolutionary studies. The results of this research make possible a better understanding of past animal distributions and [hu]man's use of those animal resources." Thus, the study of archaeological and/or paleontological organic residues may enable us to improve wildlife management strategies by providing information related to targets for conservation or restoration.

In this paper, I discuss the relevance of archaeological protein residue analysis to wildlife management issues. Beginning with a brief explanation of why protein is a suitable target molecule for studies of this type, I continue with examples of modern wildlife management issues that could be addressed via residue analysis and conclude with suggestions for research needed to further develop the potential of protein-based studies.

\section{Protein Residues}

There is room for debate about which type of residue is best for revealing meaningful information about past environments given the variety of residues that preserve in archaeological and paleontological samples. On one extreme, compounds such as DNA or RNA provide relatively clear species-level identifications of the residue-contributing organism(s). Although seemingly ideal in this respect, the fragile nature of these compounds combined with their relatively low abundance may impede their survival over long periods of time (but see Pääbo 1985; Shanks et al. 2004). In addition, the successful examination of ancient DNA requires that researchers implement stringent and potentially costly protocols in order to prevent the contamination of ancient samples with modern DNA (Kolman and Tuross 2000).

At the other extreme, compounds such as fatty acids, and lipids in general, are known to resist degradation due to their hydrophobic nature, which impedes microbial attack. Further, their molecular abundance in organism tissues provides a greater 
statistical likelihood for their survival. However, the interpretive power provided by analysis of these compounds is limited by their non-specificity; in most cases lipids can only be sourced to very broad classes of organism such as 'fish,' 'mammal' or 'seeds' (Malainey et al. 1999, but see Mirabaud et al. 2007). Although useful for addressing many relevant questions, these compounds have less to offer when fine-scale taxonomic discrimination across a wide variety of potential residue-contributing organisms is desired.

Between the extremes of DNA and lipids are proteins. As important structural and functional components, proteins, like lipids, are abundant in organism tissues. More importantly, as a direct product of an underlying genetic code, the sequence of amino acids within individual proteins is highly specific and therefore capable of providing greater taxonomic resolution than lipids. Additionally, many proteins are specific to particular tissues, meaning that it may be possible to determine not only which taxon, but which specific portions of a taxon, are present in an artifact.

Despite the assumption that proteins are poor candidates for preservation over time due to characteristics such as their hydrophilic nature (with the exception of proteins such as collagen, which are hydrophobic), susceptibility to degradation by microorganisms, and/or tendency to be modified when cooked, research, particularly by Craig and Collins (2000, 2002), suggests that a particular but common set of circumstances may counteract these sources of loss. Specifically, it has been demonstrated that proteins bind to mineral, e.g., ceramic, matrices via the interplay of inter and intra-molecular non-covalent forces including ion exchange, water bridges, Van der Waal bonding, and hydrophobic interactions (Figure 1). Subsequently, these residues are difficult to remove and detect without the use of corrosive acids, strong detergents, and/or highly sensitive analytical equipment (Craig and Collins 2002; Stevens et al. 2010). In addition to binding proteins, such matrices may also facilitate preservation by trapping organics within small pore spaces that restrict the access of microorganisms (Brady and Weil 2002:514) and/or within complex organic conglomerates (Kleber et al. 2007). The result of these interactions, despite not being completely understood, is that proteins have been recovered from a variety of contexts in which they are closely bound to a mineral surface. Schweitzer et al. (2009), Heaton et al. (2009) and Yohe et al. (1991), to give a few examples, verify that proteins survive in fossilized bone, ancient ceramic artifacts, and groundstone implements. Although additional work is needed to fully evaluate the nature of protein-mineral interactions, these examples demonstrate that proteins bind to mineral matrices and that they can survive and be recovered after hundreds or even thousands of years. In sum, this potential, when combined with the identification specificity that proteins provide, suggests that ancient proteins are well-suited to provide meaningful information about past environments and humanenvironment interactions.

\section{Case Studies}

Currently, there are no studies of zooarchaeological protein residues that can be called upon to illustrate the value of these residues for conservation biology and restoration ecology. Therefore I am limited to describing several instances in which residue analysis could provide data that are unavailable via standard traditional zooarchaeological analysis, data that are critical to resolution of a modern conundrum in conservation biology.

Mountain Goats in Washington State-Lyman $(1996,1998)$ discusses the status of mountain goats in Olympic National Park in northwestern Washington State. Although 'introduced' to the area in 1928, it is unclear whether this species should be considered as native or exotic. As Lyman notes, this is due to two underlying issues. First, the National Park Service definitions of 'native' and 'exotic' are poorly constructed, leaving room for contradictory interpretations. Second, however, is the fact that the paleozoological record from this region is poor, leaving park managers with little prehistoric data. This problem is compounded by the ambiguous, pre-1920's historic record and conflicting public opinion today regarding whether or not extant goats should be eradicated. Clearly, more information is needed to resolve this debate.

At the 2009 Society for American Archaeology annual conference in Atlanta, Georgia, archaeological protein chemist Caroline Solazzo presented a summary of results from an ongoing project involving Salish blankets. Specifically, Solazzo et al. (2009) used a proteomics-based method to identify the hair of contributing species found in late nineteenth to early twentieth century blankets from Washington. Testing for dogs, sheep and goats in particular, Solazzo et al. convincingly demonstrated that the blanket fibers under study contained peptides derived from both sheep and goats.

It is unclear whether Solazzo et al. are aware of the debate regarding mountain goats in Washington. However, considering that Salish-speaking tribes are native to the Olympic Peninsula, it is relevant to 
suggest that the results presented by Solazzo et al. may shed light on the issue of goats in the Olympic goat controversy. Simply put, if pre-1920's Salish blankets from the Olympic Peninsula can be shown to contain mountain goat hair, then a more convincing argument for the native status of this species in the area can be made. Certainly, there are other factors that must be weighed if such evidence is to be used, such as the ability to distinguish mountain goat hair proteins from similar native or non-native species (e.g., Ovis, Capra sp.), or the likelihood that blankets were traded over long distances. Nevertheless, the point here is not to suggest that Solazzo et al. (2009) have provided a definitive answer to this particular issue, but rather to illustrate that useful biogeographic evidence can be obtained through archaeological protein residue analysis.

Missouri Elk-In a similar vein, Harpole (2004) reports on the difficulty of ascertaining the prehistoric status of the North American elk (Cervus canadensis) in a proposed reintroduction area consisting of ten counties in southeastern Missouri. Although elk were certainly native to Missouri in general, as suggested by paleozoological and historic records alike, debate exists regarding their native status within the reintroduction area. Decision-making is hindered by a lack of evidence, with proponents seeming to favor reintroduction of elk for economic (e.g., hunting, tourism) rather than for ecological reasons.

Of the archaeological sites within the region that Harpole considered, only one, the undated, mixeddeposit, open-air Lepold site, was found to have elk remains. As Harpole points out, this site is hardly representative considering that it lies east of the Ozark Escarpment in the Mississippi River floodplain, an area that is considerably different from the proposed reintroduction sites. For the remaining sites, an important question must be addressed: are elk absent from the record because they were never there, or are they absent because the soil and weather conditions of the Ozark Plateau and surrounding areas are generally not conducive to the preservation of faunal remains?

As previously discussed, the preservation of protein appears to be favored by sequestration in mineral matrices, particularly clays. Ceramic artifacts, then, are ideally suited for protein residue analysis. In Missouri, pottery is commonly recovered from archaeological sites, including sites on the Ozark Plateau (Lynott et al. 2000). To date, no research has been conducted to ascertain the likelihood of protein survival in these artifacts, but the successful recovery of protein residues in this case would go a long way toward resolving the debate over the appropriateness of elk reintroduction efforts.

Pacific Otters-As discussed by Valentine et al. (2008), extensive hunting during the eighteenth and nineteenth centuries led to drastic reductions in sea otter (Enbydra lutris) populations in the eastern Pacific Ocean, particularly in Oregon, where they were extirpated. Attempted reintroductions of sea otters to this region have been largely unsuccessful despite more fruitful results in areas to the north, and recent research has provided several important clues as to why the Oregon reintroduction failed.

Studies of morphological (Wilson et al. 1991) and genetic (Valentine et al. 2008) variation suggest that there are several distinct genotypes associated with three different subspecies of sea otter: the common sea otter (E. l. lutris), the southern sea otter (E. l. nereis), and the northern sea otter (E. l. Kenyoni). In the case of Oregon reintroduction efforts, a population of northern sea otters was transplanted from Alaska. However, examination of the zooarchaeological record via morphometric (Lyman 1988) and DNA (Valentine et al. 2008) studies demonstrated that this particular subspecies has never been common in Oregon and that it is likely not well-suited to the unique environmental conditions of the Oregon coast. Instead, the extirpated populations more closely resemble southern sea otters currently living in California. Although time will tell, the zooarchaeological evidence indicates that the latter taxon would provide better (that is, more likely to survive and reproduce) candidates for transplantation.

I suggest that archaeological proteins may provide a supporting or alternative line of evidence in this, or similar cases. It is well-documented, for example, that particular proteins can vary in structure not only across but within species (Zeidler 2000). Such proteins perform the same essential function(s) and have similar structures. However, they feature subtle variations in amino acid composition as a result of genetic mutations, allowing them to be distinguished through relatively simple procedures such as gel electrophoresis. Several studies (e.g., Mateu-Andrés 2004) have used these differences as a means of measuring overall genetic diversity in extant populations of threatened species.

Although archaeological samples would likely provide unique challenges, as discussed below, a similar approach could be used as a method for distinguishing different subspecies in the archaeological record. The real benefit is that samples could be obtained not just from skeletal remains or tissues, but from many other 


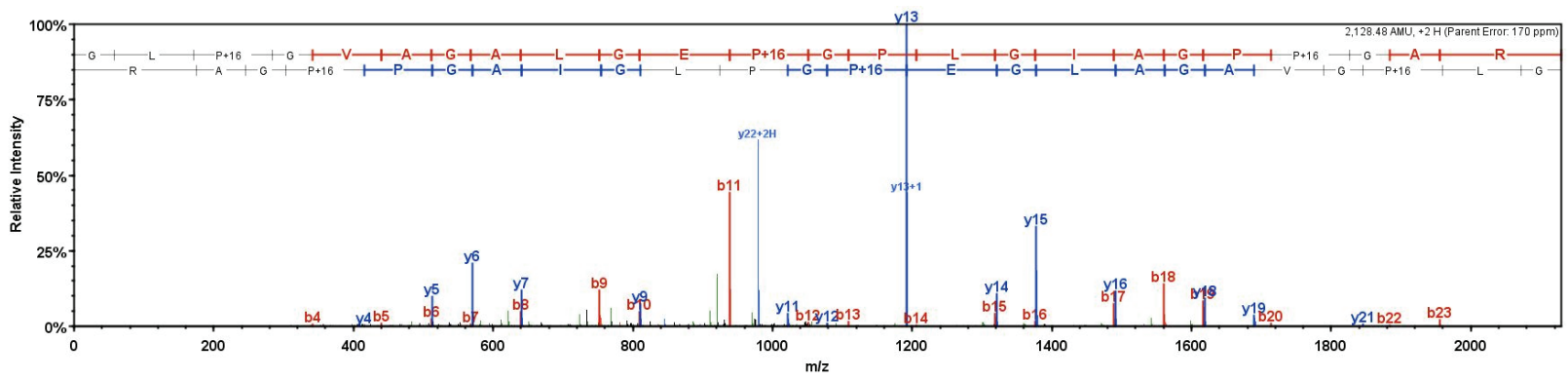

Q28668|CO1A2_RABIT (100\%), 53,129.5 Da
Collagen alpha-2(I) chain (Fragment) OS=Oryctolagus cuniculus GN=COL1A2 PE=2 SV=1
2 unique peptides, 3 unique spectra, 19 total spectra, $70 / 526$ amino acids (13\% coverage)

\begin{tabular}{|c|c|c|c|c|}
\hline 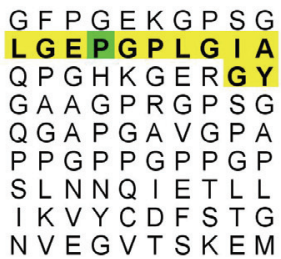 & 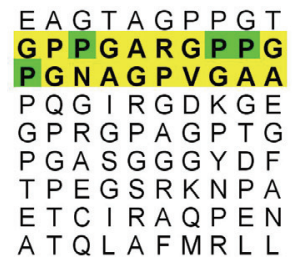 & 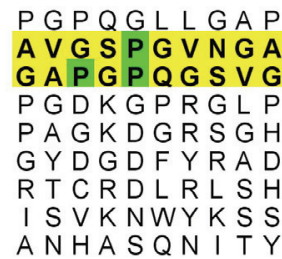 & $\begin{array}{l}G \text { I L L PGSR G } \\
\text { PGEAGRDGN } \\
P \text { T K KHGNRG } \\
G \text { I KGHNGLQG } \\
P G T V G P A G L R \\
Q P R S P P S L R P \\
P E W S S G Y Y W I \\
K A K K H V W L G E\end{array}$ & $\begin{array}{l}\text { GLPGVAGA } \\
D G P P G R D G \\
P A G S \text { I } P \text { P } \\
G L A G Q H G D \\
Q G S Q G P A G \\
Y E V D A T L K \\
N Q G C T M D A \\
N G G T Q F E Y \\
T G N D K A V\end{array}$ \\
\hline
\end{tabular}

Figure 2. Representative mass spectrum (top) and recovered peptide sequences (bottom) from a 750 year old jackrabbit tibia from the Goodman Point Pueblo (5MT604). Because jackrabbit is not included in typical protein databases, a match to the European rabbit, Oryctolagus cuniculus, was assumed to reflect a correct identification.

contexts (e.g., mineral matrices) where proteins have been demonstrated to preserve. Further, using this method as an alternative to DNA testing may reduce the associated cost and/or the amount of time and training required for sample processing (Buckley et al. 2010; Zeidler 2000, but also see cautionary comments). In sum, this strategy may represent an opportunity to gain meaningful evidence at a lower cost in the absence of well-preserved skeletal remains.

Other Recent Examples-Several recent archaeological studies, despite not being tailored to address conservation questions in particular, suggest the plausibility of using protein-based approaches for revealing relevant information. For example, LC-MS analysis of a $\sim 750$ year old jackrabbit (Lepus sp.) tibia from the Goodman Point Pueblo (5MT604) site in southwestern Colorado reveals the presence of intact collagen peptides (Figure 2). Although additional research is needed in order to establish appropriate reference databases, this result is important in that traditional zooarchaeological analyses have not always been able to distinguish between the various leporid species that are present in this region (see Yang et al. 2005 for a successful DNA approach).

In another example, Buckely et al. (2010), using mass spectrometry, recently developed a method for distinguishing between Neolithic-era sheep (Ovis sp.) and goat (Capra sp.) remains on the basis of a single collagen peptide. The value of this technique, aside from its expense relative to DNA-based methods, is that it provides a new means to distinguish between morphologically ambiguous (e.g., immature, highly fragmented) specimens from closely related species. Insofar as the value of protein analysis to conservation science is concerned, this is clearly relevant.

To summarize, the preceding examples have demonstrated the potential of protein residue analysis for addressing questions of wildlife management. However, the realization of this potential requires further method development and increased communication between archaeologists, analytical chemists, and conservation scientists. In the next section, I discuss several key issues that need to be addressed before protein-based studies can be applied to conservation science over broad temporal and/or spatial scales.

\section{Future Research}

Despite some successes in the recovery and identification of archaeological protein residues, several limitations have hindered the widespread application of protein-based studies, most of which are rooted in the shortage of published methodological research (but see Barnard et al. 2007; Buckley et al. 2010; Brandt et al. 2002; Craig and Collins 2000, 2002; Solazzo et al. 2008; 
Stevens et al. 2010). Too often, it seems that the focus of residue research has been on providing archaeologically meaningful results rather than on addressing fundamental assumptions regarding the behavior of organic chemicals over long periods of time and the suitability of the analytical techniques that have been applied for recovering and identifying archaeological proteins.

Immunological assay, for example, has been employed in a number of cases with apparent success. Despite these results, there is legitimate reason to question the utility of immunoassay given that ancient proteins are likely to be contaminated with a variety of proteins from other sources (e.g., soil bacteria) that can ultimately yield false positives (Brandt et al. 2002), particularly if ample consideration is not given to testing the antibodies used. Further, the denaturation, degradation, and/or modification of proteins due to cooking processes, bacterial activity or other sources of weathering may sufficiently alter proteins so that they no longer react with antibodies in an immunological assay (Barnard et al. 2007). Although not insurmountable, these challenges have not been adequately addressed via comprehensive analyses that detail the effects of these factors in terms of the success or failure of immunological techniques. Multiple, independent analyses, as recommended by Brandt et al. (2002), may remedy this problem to some degree, but further experimental research into the chemical behavior of degraded proteins will be essential to achieve acceptance by the scientific community at large.

Another limitation that has not been adequately considered is the influence of context on both the quality and quantity of preserved protein residue. To what degree, for example, do clay types differ in terms of their ability to sorb and preserve proteins? It is wellestablished that the plasticity, shrink/swell capability, and ion-exchange capacity of clays can differ greatly depending on the ratio of kaolinite to montmorillinite present (Shepard 1956). However, most relevant archaeological publications dealing with the analysis of proteins in ancient and/or experimental samples typically do not include a detailed analysis of ceramic composition. This is understandable considering the workload involved in both protein and ceramic analyses. Such cases represent a missed opportunity for collaboration between residue analysts and geologists/geoarchaeologists that would likely result in improved methodology.

Similarly, the effects of environmental conditions such as temperature, humidity and $\mathrm{pH}$ have not been considered in detail. Most successful archaeological protein studies have been conducted on samples acquired from relatively cold, dry and/or anoxic environments, which makes sense considering that these conditions are known to favor the preservation of organic compounds. However, the limits of these variables have not been fully ascertained in experimental protein studies, particularly in regards to $\mathrm{pH}$, a factor that could greatly influence both the type and quantity of ceramic-bound protein by altering the net charge of proteins and/or inhibiting/promoting their decay. Without additional knowledge to this effect, sampling strategies are reduced to guesswork and key opportunities may be missed due to a potentially misguided assumption that proteins are not likely to preserve under certain conditions.

Lastly, much current research is limited by the failure to report quantitative data (but see Craig and Collins 2000, 2002; Shanks et al. 2004; Solazzo et al. 2008; Stevens et al. 2010). Without knowing quantitative information, such as the amount of protein that sorbs to ceramic matrices, the percentage of total protein recovered using different extraction strategies, the quantity of protein residues recovered from archaeological samples, or a probability estimate of a particular protein match, it is difficult to gauge the validity of results. These data are relatively easy to obtain via the use of total organic carbon analysis, spectrometric assays, statistical analyses, and other methods. It is therefore surprising that archaeologists have not taken full advantage of these strategies considering that they lend much-needed credibility to protein residue analysis. For future projects, it will be essential that such data are included in published reports so that comparisons can be made across studies.

\section{Conclusion}

Through discussion of these examples I have argued that protein residue analysis is a valuable form of paleobiological inquiry in conservation science. Such research would enable better wildlife management by revealing a more accurate picture of prehistoric biogeography and of the interaction of prehistoric humans with past environments. Although other residue types, including DNA, lipids, and alkaloids, may provide similarly useful information, the unique characteristics of proteins, particularly in terms of their widespread occurrence and apparent potential for preservation within mineral matrices, make them ideal candidates for applied archaeological research. 
In order for this method of analysis to reach its fullest potential, however, scientists must turn their attention to developing a reliable and valid methodology. To accomplish this task, we need to challenge long-held assumptions, fill in the aforementioned gaps in knowledge, and promote multidisciplinary approaches. My critique is not an attempt to challenge or downplay important discoveries to date. Rather, I seek to demonstrate the value of the work done while simultaneously pointing out areas for improvement. As these challenges are met, protein residue analysis will hopefully come to be seen not just as a method of studying the past, but as one of several valuable archaeological tools that can be used in the development of management practices that result in sustainable ecosystems.

\section{Acknowledgements}

This work was sponsored in part by the National Science Foundation Archaeometry Technical Development Grant number 0822196. I thank Steve Wolverton, Charles Randklev, R. Lee Lyman and two anonymous reviewers for comments. Jackrabbit specimens were provided by Crow Canyon Archaeological Center. Barney Venables and Stan Stevens assisted in protein extraction and LC-MS analysis.

\section{References Cited}

Barnard, H., L. Shoemaker, O. E. Craig, M. Rider, R. E. Parr, M. Q. Sutton, and R. M. Yohe II. 2007. Introduction to the Analysis of Protein Residues in Archaeological Ceramics. In Theory and Practice of Residue Analysis, edited by H. Barnard and J. Eerkens, pp. 216231. BAR International Series 1650. Archaeopress, Oxford, UK.

Brady, N. C., and R. R. Weil. 2002. The Nature and Property of Soils. Prentice Hall, NJ.

Brandt, E., I. Wiechmann, and G. Grupe. 2002. How Reliable are Immunological Tools for the Detection of Ancient Proteins in Fossil Bones. International Journal of Osteoarchaeology 12:307-316.

Buckley, Mike, Sarah Whitcher Kansa, Sarah Howard, Stuart Campbell, Jane Thomas-Oates and Matthew Collins. 2010. Distinguishing Between Archaeological Sheep and Goat Bones using a Single Collagen Peptide. Journal of Archaeological Science 37:13-20.

Callicott, J. B. 2002. Choosing Appropriate Temporal and Spatial Scales for Ecological Restoration. Journal of Biosciences 27:409-420.
Cannon, K. P., and M. B. Cannon. 2004.

Zooarchaeology and Wildlife Management in the Greater Yellowstone Ecosystem. In Zooarchaeology and Conservation Biology,edited by R. L. Lyman and K. P. Cannon, pp. 45-60. University of Utah Press, Salt Lake City, UT.

Craig, O. E., and M. J. Collins. 2000. An Improved Method for the Immunological Detection of Mineral Bound Protein Using Hydrofluoric Acid and Direct Capture. Journal of Immunological Methods 236:89-97.

Craig, O. E., and M. J. Collins. 2002. The Removal of Protein Residues from Mineral Surfaces: Implications for Residue Analysis of Archaeological Materials. Journal of Archaeological Science 29:1077-1082.

Eerkens, J. W., and Hans Barnard. 2007. Introduction. In Theory and Practice of Archaeological Residue Analysis, edited by H. Barnard and J. W. Eerkens, pp. 1-7. BAR International Series 1650. Archaeopress, Oxford, UK.

Evershed, R. P., and N. Tuross. 1996. Proteinaceous Material from Potsherds and Associated Soils. Journal of Archaeological Science 23:429-436.

Harpole, J. L. 2004. Zooarchaeological Implications for Missouri's Elk (Cervus elaphus) Reintroduction Effort. In Zooarchaeology and Conservation Biology, edited by R. L. Lyman and K. P. Cannon, pp. 103-115. University of Utah Press, Salt Lake City, UT.

Heaton, K., C. Solazzo, M. J. Collins, J. Thomas-Oates, and E. T. Bergström. 2009. Towards the Application of Desorption Electrospray Ionisation Mass Spectrometry (DESI-MS) to the Analysis of Ancient Proteins from Artefacts. Journal of Archaeological Science 36:2145-2154.

Kleber, M., P. Sollins and R. Sutton. $2007 . \quad$ A conceptual model of organo-mineral interactions in soils: self-assembly of organic molecular fragments into zonal structures on mineral surfaces. Biogeochemistry 85:9-24.

Kolman, Connie J. and Noreen Tuross. 2000. Ancient DNA Analysis and Human Populations. American Journal of Physical Anthropology 111:5-23.

Loy, T. H. 1983. Prehistoric Blood Residues. Detection on Tool Surfaces and Identification to Species of Origin. Science 220:1269-1271.

Lyman, R. L. 1988. Zoogeography of Oregon Coast Marine Mammals: The Last 3000 Years. Marine Mammal Science 4:247-264. 
Lyman, R. L. 1996. Applied Zooarchaeology: The Relevance of Faunal Analysis to Wildlife Management. World Archaeology 28:110-125.

Lyman, R. L. 1998. White Goats, White Lies: The Abuse of Science in Olympia National Park. University of Utah Press, Salt Lake City, UT.

Lynott, M. J., H. Neff, J. E. Price, J. W. Cogswell, and M. D. Glascock. 2000. Inferences about Prehistoric Ceramics and People in Southeast Missouri: Results of Ceramic Compositional Analysis. American Antiquity 65:103-126.

Malainey, M. E., P. Pryzybylski, and B. L. Sherriff. 1999. The Fatty Acid Composition of Native Food Plants and Animals of Western Canada. Journal of Archaeological Science 26:83-94.

Mateu-Andrés, I. 2004. Low Levels of Allozyme Variability in the Threatened Species Antirrbinium subbaeticum and $A$. pertegasii (Scrophulariaceae): Implications for Conservation of the Species. Annals of Botany 94:797-804.

Mirabaud, Sigrid, Christian Rolando and Martine Regert. 2007. Molecular Criteria for Discriminating Adipose Fat and Milk from Different Species by NanoESI MS and MS/MS of their Triacylglycerols: Application to Archaeological Remains. Analytical Chemistry 79:6182-6192.

Pääbo, S. 1985. Molecular Cloning of Ancient Egyptian Mummy DNA. Nature 314:644-645.

Schweitzer, M. H., W. Zheng, C. L. Organ, R. Avci, Z. Suo, L. M. Freimark, V. S. Lebleu, M. B. Duncan, M. G. Vander Heiden, J. M. Neveu, W. S. Lane, J. S. Cottrell, J. R. Horner, L. C. Cantley, R. Kalluri, and J. M. Asara. 2009. Biomolecular Characterization and Protein Sequences of the Campanian Hadrosaur B. canadensis. Science 324:626-631.

Shanks, O. C., M. Kornfield, and W. Ream. 2004. DNA and Protein Recovery from Washed Experimental Stone Tools. Archaeometry 46:663-672.

Shepard, A. O. 1956. Ceramics for the Archaeologist. Carnegie Institution of Washington, Washington, D.C.

Solazzo, C., W. W. Fitzhugh, C. Rolando, and C. Tokarski. 2008. Identification of Protein Remains in Archaeological Potsherds by Proteomics. Analytical Chemistry 80:4590-4597.

Solazzo, C., S. Heald, M. Ballard, E. Cappelini, and M. Collins. 2009. Fiber Identification in Salish Blankets by
Proteomics. Presented at the 74th Annual Meeting of the Society for American Archaeology, Atlanta, GA.

Stevens, S. M., Jr. S. Wolverton, B. Venables, A. Barker, K. Seeley, and P. Adhikari. 2010. Evaluation of Microwave-assisted Enzymatic Digestion and Tandem Mass Spectrometry for the Identification of Protein Residues from an Inorganic Solid Matrix: Implications in Archaeological Research. Analytical and Bioanalytical Chemistry 396:1491-1499.

Valentine, K., D. A. Duffield, L. E. Patrick, D. R. Hatch, V. L. Butler, R. L. Hall, and N. Lehman. 2008. Ancient DNA Reveals Genotypic Relationships among Oregon Populations of the Sea Otter (Enhydra lutris). Conservation Genetics 9:933-938.

Wilson, Don E., Michael A. Bogan, Robert L. Brownell, Jr., A. M. Burdin and M. K. Maminov. 1991. Geographic Variation in Sea Otters, Enhydra lutris. Journal of Mammology 72:22-36.

Wolverton, S., J. H. Kennedy, and J. D. Cornelius. 2007. A Paleozoological Perspective on White-tailed Deer (Odocoileus virginianus texana) Population Density and Body Size in Central Texas. Environmental Management 39:545-552.

Yang, Dongya, Joshua R. Woiderski and Jonathan C. Driver. 2005. DNA Analysis of Archaeological Rabbit Remains from the American Southwest. Journal of Archaeological Science 32:567-578.

Yohe II, R. M., M. E. Newman, and J. S. Schnieder. 1991. Immunological Identification of Small-Mammal Proteins on Aboriginal Milling Equipment. American Antiquity 56:659-666.

Zeidler, M. 2000. Electrophoretic Analysis of Plant Isozymes. Biology 38:7-16.

\section{Biosketch}

Andrew Barker has a Master's of Science in Applied Geography emphasizing environmental archaeology, and he is a PhD student in the Department of Biological Sciences at the University of North Texas. His research focuses on proteomics in archaeological residue analysis and metabolomics in toxicology. 